\title{
Copper-Catalyzed Chemoselective Cross-Coupling Reaction of Thioamides and $\alpha$-Diazocarbonyl Compounds: Synthesis of Enaminones
}

\author{
Arpal Pal $^{\mathrm{a}}$, Naga D. Koduri ${ }^{\mathrm{a}}$,ZhiguoWang ${ }^{\mathrm{a}}$, Erika Lopez Quiroz ${ }^{\mathrm{a}}$, Alexandra Chong ${ }^{\mathrm{a}}$, Matthew \\ Vuong $^{\mathrm{a}}$, Nisha Rajagopal ${ }^{\mathrm{a}}$, Michael Nguyen ${ }^{\mathrm{a}}$, Kenneth P. Roberts ${ }^{\mathrm{a}}$, and Syed R. Hussaini ${ }^{\mathrm{a}^{*}}$ \\ ${ }^{a}$ Department of Chemistry and Biochemistry, The University of Tulsa, 800 S Tucker Dr, Tulsa, Oklahoma 74104, USA
}

\begin{abstract}
The development of operationally simple and cost-effective methods for C-C bond formation reactions are highly important in pharmaceutical, agrochemical and material research. In this article we describe the first copper-catalyzed cross-coupling reaction of thioamides with acceptor/acceptor-substituted and acceptor-only substituted $\alpha$-diazocarbonyl compounds to yield enaminones. The reaction shows broad substrate scope in terms of thioamides and diazocarbonyl compounds. Primary, secondary and tertiary thioamides all give enanminones when reacted with $\alpha$-diazodiesters, $\alpha$-diazoketoesters, $\alpha$-diazodiketones, $\alpha$-diazoketoamides, $\alpha$-diazoesteramides, $\alpha$ diazoketosulfones and $\alpha$-diazomonoketones.
\end{abstract}

\author{
Enaminone \\ Copper \\ Heterocycle \\ Diazocarbonyl compounds \\ Cross-coupling
}

\section{Introduction}

Copper-catalyzed reactions of diazocarbonyl compounds contribute to a number of valuable transformations in organic synthesis. ${ }^{1-8}$ Numerous methods are known for the construction of $\mathrm{C}-\mathrm{C}$ and $\mathrm{C}-\mathrm{X}(\mathrm{X}=\mathrm{N}, \mathrm{O}, \mathrm{S}$ and $\mathrm{Si})$ bonds using coppercarbenoids. ${ }^{1}$ Despite these significant advances, the coppercatalyzed cross-coupling reaction of thioamides and $\alpha$ diazocarbonyl compounds for the synthesis of enaminones have never been reported. ${ }^{9}$ Here, for the first time, we disclose the synthesis of enaminones via a copper-catalyzed chemoselective cross-coupling of thioamides and $\alpha$-diazocarbonyl compounds.

Enaminones are versatile synthetic intermediatesin organic chemistry. ${ }^{10-14}$ They are widely used for the construction of heterocycles and pharmaceutically active compounds. ${ }^{10-14}$ Enaminones are also found to exert anticonvulsant, ${ }^{15}$ proteasome inhibition, ${ }^{16}$ molluscicidal and larvicicidal ${ }^{17}$ activities. Because of their importance, the development of new and efficient methods for the synthesis of enaminones is an active area of research. ${ }^{18-24}$

A variety of methods are available for the synthesis of enaminones. ${ }^{10-14}$ Among the reported methods, the Eschenmoser sulfide contraction (ESC) reaction has been used extensively for the construction of enaminones. ${ }^{14,25,26}$ However, the ESC reaction suffers from significant drawbacks. The preparation of suitable $\alpha$-bromocarbonyl compounds can be difficult. The ESC also requires a long time for completion. ${ }^{27-30}$ Furthermore, the ESC method is unsuccessful in coupling sterically hindered thioamides with $\alpha$-halocarbonyl compounds. ${ }^{14,}{ }^{31}$ Modified versions of the ESC reaction have emerged to overcome these shortcomings. ${ }^{14,}{ }^{26}$ One such reaction is the $\mathrm{Rh}(\mathrm{II})$ and the $\mathrm{Ru}(\mathrm{II})-$ catalyzedcoupling of thioamides with $\alpha$-diazocarbonyl groups. ${ }^{14}$, ${ }^{32-34}$ One problem associated with the $\mathrm{Rh}(\mathrm{II})$ and the $\mathrm{Ru}(\mathrm{II})-$ catalyzed versions of this reaction is the competing formation of the homocoupled products. ${ }^{35}$ Another issue is that, in the coupling of thioamides with the monocarbonyl diazo compounds, the reaction stops at the thioether stage. A large excess of thiophile is needed to convert the thioethers into enaminones. ${ }^{35}$ There are also no reports of the coupling of the thioformamides and diazo compounds for the formation of enaminones. Coupling with thioformamides could provide disubstituted enaminones that are useful intermediates in natural product synthesis. ${ }^{36}$ Furthermore, $\mathrm{Rh}_{2}(\mathrm{OAc})_{4}$ and $\mathrm{Ru}(\mathrm{II})$-catalysts used in transformation are more expensive than common $\mathrm{Cu}$ catalysts that have been used in the generation of copper carbenoids. ${ }^{1}$ To address these challenges, we tested selected copper catalysts (Table 1). Copper is not a precious metal, and many copper catalysts are better in avoiding dimerization reactions than $\mathrm{Rh}_{2}(\mathrm{OAc})_{4} \cdot{ }^{3}$ Copper catalysts also have a broad tolerance of functional groups present on substrates. ${ }^{37}$

\section{Results and discussion}

We initiated our studies with the screening of copper catalysts for the coupling of thiolactam 1a and diazoester $\mathbf{2 a}$ (Table 1). All catalysts shown in Table 1 are known to generate copper carbenoids from acceptor-substituted diazo compounds. ${ }^{1}$, 38, 39 We tested $\mathrm{Cu}(\mathrm{OTf})_{2}(5 \mathrm{~mol} \%)$ as a catalyst in benzene at $90^{\circ} \mathrm{C}$ and monitored the progress of the reaction up to 26 hours. However, the reaction did not undergo complete conversion into the product and starting materials remained (Table 1, entry 1). A higher yield of 3aa was obtained when 1,2-dichloroethane was used as the solvent ( Table 1, compare entries 1-3). The best yield of 3aa (92\%) was obtained when the reaction was carried out with (CuOTf) $)_{2}$ Tol in 1,2-dichloroethane (Table 1, entry 7). Other electrophilic copper catalysts (Table 1, entries 9, 10 and 
11) failed to completely consume 1a in 26 hours. The use of $\mathrm{CuCl}, \mathrm{CuBr}$ and $\mathrm{CuI}$ gave reduced yields (Table 1, entries 12-14) and 1a did not undergo complete conversion into 3aa. When anhydrous $\mathrm{CuSO}_{4}$ was used, only $15 \%$ conversion 1a into 3aa was observed (Table 1 entry 15). Use of (IPr)CuCl and CuTC did not improve the yield ( Table 1, entries 16 and 17) and $\mathrm{Cu}(\mathrm{acac})_{2}$ showed scarce conversion of 1a into 3aa (Table 1, entry 18).

Table 1: Optimization of Reaction Conditions ${ }^{a}$

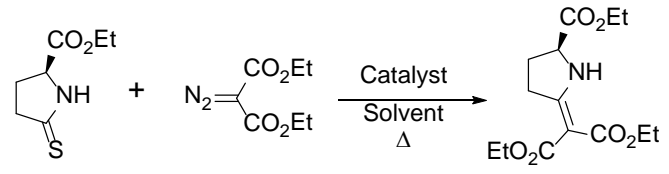

$1 \mathbf{a}$

$2 \mathbf{a}$

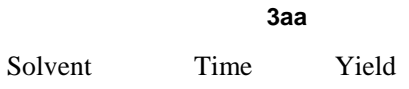

Entry Catalys

(h)

Cu(OTf)

Benzene 26

40

2. $^{b} \quad \mathrm{Cu}(\mathrm{OTf})_{2}$

DCB

3. ${ }^{c} \quad \mathrm{Cu}(\mathrm{OTf})_{2}$

DCE

$4^{c} \quad(\mathrm{CuOTf})_{2} \cdot \mathrm{Tol}$

Benzene

19

60

5. $\quad(\mathrm{CuOTf})_{2} \cdot \mathrm{Tol}$

Toluene

$$
18
$$

DCB

$6^{{ }^{c}} \quad(\mathrm{CuOTf})_{2} \cdot \mathrm{Tol}$

DCE

$7^{c} \quad(\mathrm{CuOTf})_{2} \cdot \mathrm{Tol}$

DCE

$$
12
$$

11

8. $^{d} \quad(\mathrm{CuOTf})_{2} \cdot \mathrm{Tol}$

DCM

26

DCE

26

26

10. ${ }^{b} \quad \mathrm{Cu}\left(\mathrm{CH}_{3} \mathrm{CN}\right)_{4} \mathrm{BF}_{4}$

DCB

DCE

26

30

11. ${ }^{b} \quad \mathrm{Cu}\left(\mathrm{CH}_{3} \mathrm{CN}\right)_{4} \mathrm{PF}_{6}$

DCE

$$
26
$$

49

13. ${ }^{b} \mathrm{CuBr}$

DCE

26

39

14. ${ }^{b} \quad \mathrm{CuI}$

DCE

26

41

15. ${ }^{b} \quad \mathrm{CuSO}_{4}$

DCE

26

15

16. ${ }^{b} \quad$ (IPr) $\mathrm{CuCl}$

DCE

26

50

17. ${ }^{b} \quad$ CuTC

DCE

26

24

18. ${ }^{b} \mathrm{Cu}(\text { aсас })_{2}$

DCE

26

trace
92\% yield without the addition of any triphenylphosphine. The same transformation with $\mathrm{Ru}(\mathrm{II})$ requires 5 equivalents of $\mathrm{PPh}_{3}{ }^{35}$ Formation of 3ag is also noteworthy as we are aware of only four reports of enaminones containing Weinreb amides. ${ }^{40-43}$

Table 2. Copper-Catalyzed Coupling Reaction of 1a with Acceptor/Acceptor-Substituted Diazo Compounds
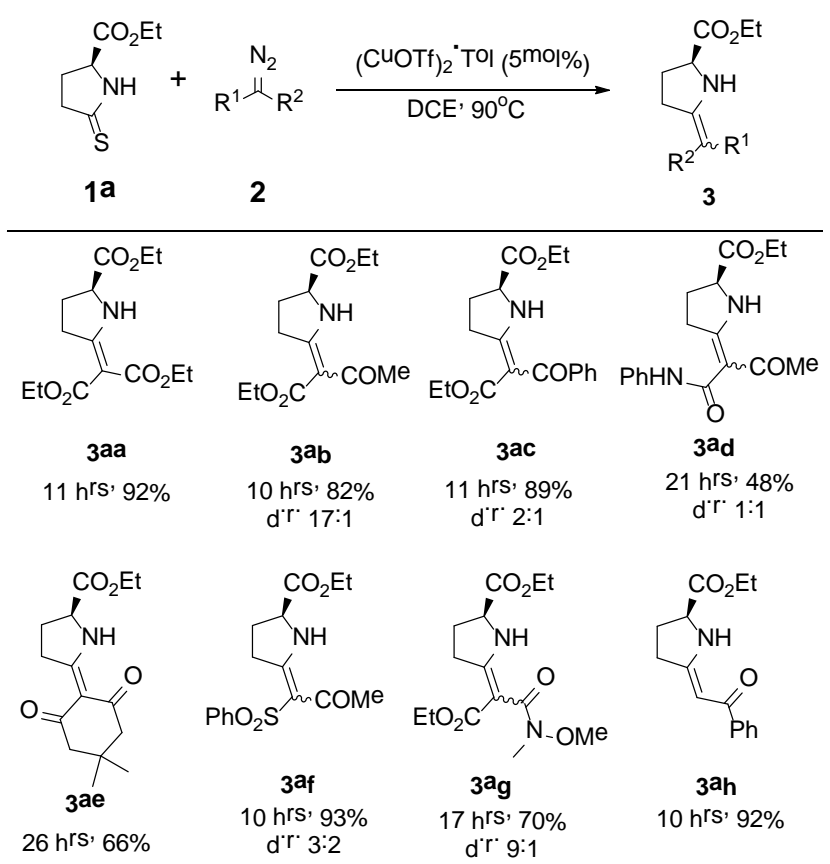

The diastereoselectivity was also probed for this coupling reaction. Only a single diastereomer3ah was obtained when $\mathbf{2 h}$ was used. Such selectivity has been observed before and is explained as a result of the greater stability of the $Z$ isomer. ${ }^{14}$ The exposure of other differently substituted diazo compounds to the reaction conditions provided mixtures of diastereomers (3ab3ad, 3af and 3ag). The selectivity observed in the case of 3ab, 3ac and 3ag is similar to the ones observed in Eschenmoser type reactions. Various explanations have been postulated for such selectivity. ${ }^{14,44}$

Next, we explored the scope of this copper-catalyzed coupling reaction with various thioamides (Table 3). Primary, secondary and tertiary thioamides were all converted into the corresponding enaminones in moderate to excellent yields (3292\%). Both cyclic (3fa, 3ea) and acyclic positioned thioamides are viable substrates in this coupling reaction. The reaction also shows excellent chemoselectivity. The $\alpha$-diazocarbonyl compounds, in the presence of copper catalysts, are known to undergo $\mathrm{N}-\mathrm{H}$ insertion, $\mathrm{C}-\mathrm{H}$ insertion and Buchner reactions. ${ }^{1}$ While evaluating the substrate scope, $\mathrm{N}-\mathrm{H}$ insertion, $\mathrm{C}-\mathrm{H}$ insertion or Buchner reaction products were never observed. Such selectivity is suspected to be due to higher nucleophilicity of sulfur compared to other functional groups and the highly electrophilic nature of the copper carbene generated from $\mathrm{Cu}(\mathrm{I})$ triflate. ${ }^{1}$ Table 3 (3da) also shows the first example of a metalcatalyzed coupling of a thioformamide and a diazo compound for the formation of an enaminone. 
Table 3. Copper-Catalyzed Coupling Reaction of Differently Substituted Thioamides

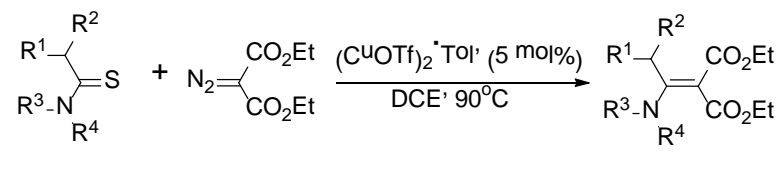

$1 \quad 2^{\mathbf{a}} \quad 3$

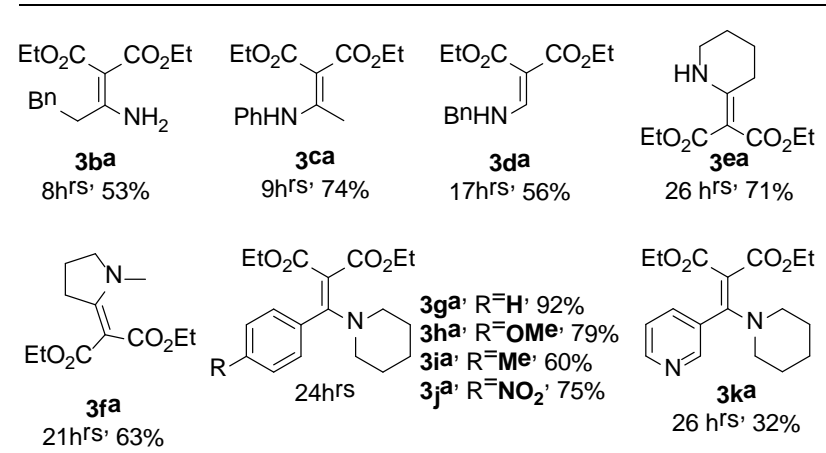

Thioethers are known to form when acceptor-only diazo compounds react with thioamides in the presence of $\mathrm{Ru}(\mathrm{II})$ catalysts. This suggests that ylides are present in this reaction. ${ }^{34,}$ ${ }^{35}$ We attempted to trap the intermediate thiocarbonyl ylide. However, the reaction of $\mathbf{1 g}$ and $\mathbf{2 a}$ in the presence of a dipolarophile4 (DMAD; dimethylacetylenedicarboxylate) did not yield cycloadduct 5 (Scheme 1A), and only 3ga was obtained. Unlike the $\mathrm{Ru}(\mathrm{II})$ catalysts, ${ }^{35}$ with $\mathrm{Cu}(\mathrm{I}) \mathrm{OTf}$, the reaction of $\mathbf{1 a}$ with $\mathbf{2 h}$ only gave the enaminone 3ah (Table 2), and formation of thioimino ether 6 was not observed (Scheme 1B). This suggests that, with $\mathrm{Cu}(\mathrm{I}) \mathrm{OTf}$, the extrusion of sulfur is not occurring just due to simple thermal activation. Furthermore, the thioimino ether $\mathbf{6}$ could be converted into the enaminone 3ah under the reaction conditions (Scheme 1B). These results support the hypothesis that copper(I) triflate catalyzes the extrusion of sulfur in this reaction. Although rarely reported, similar metal and acid-catalyzed -sulfur extrusions have been observed with zinc, nickel, $\mathrm{BF}_{3}$ and TFA in the Eschenmoser sulfide contraction reaction. ${ }^{14,45-47}$

$A^{*}$

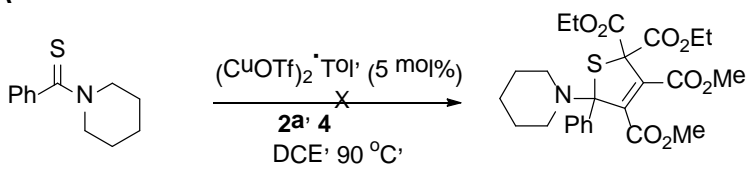

$1 \mathrm{~g}$

$24 \mathrm{~h}$

5

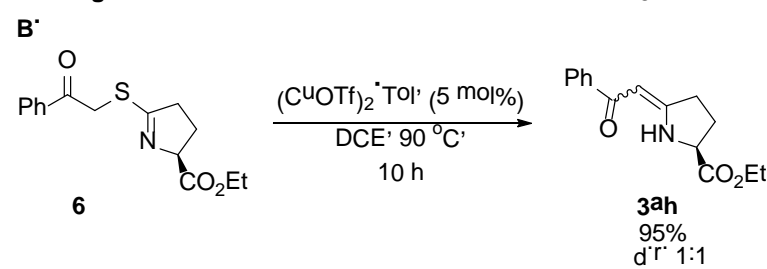

Scheme 1. Mechanistic Experiments
On the basis of these experimental observations and our previous studies, ${ }^{34,35}$ a mechanism is proposed for this coppercatalyzed coupling reaction (Scheme 2). The reaction of a copper complex with $\alpha$-diazocarbonyl compounds generates the coppercarbenecomplexe8. The nucleophilic attack of thioamide to the copper-carbene complex gives the copper-associated sulfur ylide9. The metal-free ylide10 can be obtained by the dissociation of copper from $\mathbf{9}$. Both the metal associated ylide9 and the metal free ylide10 can undergo electrocyclization to form episulfide11. Copper(I) triflate assists in the formation of episulfide11 and the subsequent extrusion of sulfur to provide enaminones. Mechanistic studies have been planned to test the validity of the proposed mechanism.

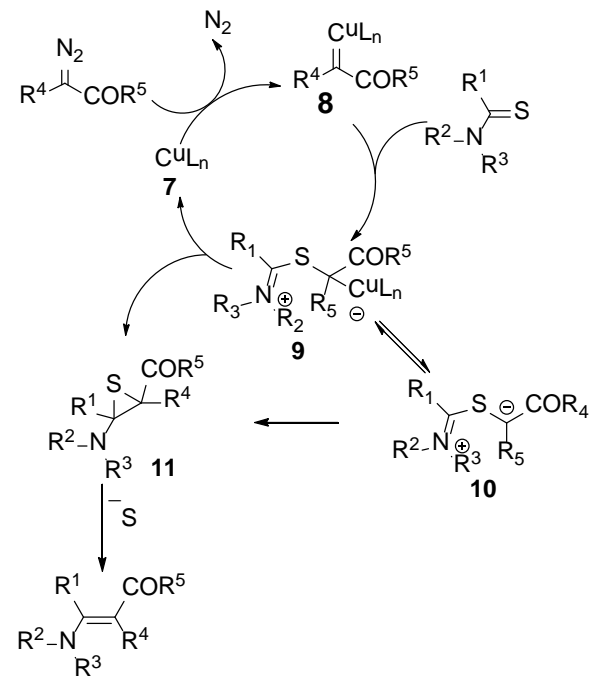

Scheme 2. Proposed Mechanism for Enaminone Formation

In conclusion, we have successfully developed an unprecedented copper-catalyzed cross-coupling reaction of thioamides with $\alpha$-diazocarbonyl compounds for the synthesis of enaminones. ${ }^{48}$ This reaction has a diverse substrate scope. It also represents the synthesis of enaminones containing the Weinreb amide, thioformamide, and sulfone functionalities which can further broaden the synthetic application of this reaction. We have also discovered a new catalytic reactivity of copper(I) triflate that enables the extrusion of sulfur from thioimino ether. Currently, we are working on the utilization of donor/acceptor-substituted diazo compounds and ester diazoacetatesin this coupling reaction.

\section{Acknowledgments}

Financial support was provided by The University of Tulsa (TU). We thank Mrs. Jennifer Holland (TU) for her help with the spectrometric measurements and Kun Miao, Ashley Johnson and Maria Castaneda (TU) for their assistance with the screening of catalysts. This work was supported by the National Science Foundation under Grant No. CHE 10487484.

\section{Supplementary data}


Experimental procedures, spectroscopic data and ${ }^{1} \mathrm{H}$ and ${ }^{13} \mathrm{C}$ spectra.

\section{References and notes}

$1 \quad$ M. P. Doyle, T. Y., M. A. Mckervey Modern Catalytic Methods for Organic Synthesis with Diazo Compounds; Wiley, New York, 1998.

2 Ford, A.; Miel, H.; Ring, A.; Slattery, C. N.; Maguire, A. R.; McKervey, M. A. Chem. Rev.2015, 115, 9981.

3 Maas, G. Top. Curr. Chem.1987, 137, 75.

4 Davies, H. M. L.; Hedley, S. J. Chem. Soc. Rev.2007, 36,

1109.

5 Xiao, Q.; Zhang, Y.; Wang, J. Acc. Chem. Res.2013, 46, 236.

6 Zhao, X.; Zhang, Y.; Wang, J. Chem. Commun. (Cambridge,

U. K.)2012, 48, 10162.

7 Su, N.; Theorell, J. A.; Wink, D. J.; Driver, T. G. Angew.

Chem. Int. Ed.2015, 54, 12942.

8 Su, N.; Theorell, J. A.; Wink, D. J.; Driver, T. G. Angew.

Chem.2015, 127, 13134.

9 Bartels, G.; Hinze, R.-P.; Wullbrandt, D. Liebigs Ann.

Chem.1980, 1980, 168.

10 Michael, J. P.; de Koning, C. B.; Gravestock, D.; Hosken, G. D.; Howard, A. S.; Jungmann, C. M.; Krause, R. W. M.; Parsons, A. S.; Pelly, S. C.; Stanbury, T. V. Pure App. Chem.1999, 979.

11 Negri, G.; Kascheres, C.; Kascheres, A. J. J. Heterocycl. Chem.2004, 41, 461.

12 Ferraz, H. M. C.; Gonçalo, E. R. S. Quím. Nova2007, 30, 957.

13 Chattopadhyay, A. K.; Hanessian, S. Chem. Commun.2015, 51,16450 .

14 Hussaini, S. R.; Chamala, R. R.; Wang, Z. Tetrahedron2015, $71,6017$.

15 Edafiogho, I. O.; Kombian, S. B.; Ananthalakshmi, K. V. V.; Salama, N. N.; Eddington, N. D.; Wilson, T. L.; Alexander, M. S.; Jackson, P. L.; Hanson, C. D.; Scott, K. R. J. Pharm. Sci.2007, 96, 2509.

16 Elliott, M. L.; Thomas, K.; Kennedy, S.; Koduri, N. D.; Hussaini, R. S.; Sheaff, R. J. Chem. Biol. Drug Des.2015, 86, 322. 17 Abass, M.; Mostafa, B. B. Bioorg. Med. Chem.2005, 13, 6133.

18 Chattopadhyay, A. K.; Hanessian, S. Chem. Commun.2015, $51,16437$.

19 Jiang, H.; He, J.; Liu, T.; Yu, J.-Q. J. Am. Chem. Soc.2016, 138, 2055.

20 Kang, Y.-W.; Cho, Y. J.; Han, S. J.; Jang, H.-Y. Org.

Lett.2016, 18, 272.

21 Li, Y.; Gao, H.; Zhang, Z.; Qian, P.; Bi, M.; Zha, Z.; Wang, Z. Chem. Commun.2016, 52, 8600.

22 Huang, P.-Q.; Ou, W.; Ye, J.-L. Org. Chem. Front.2015, 2,

1094.

23 Shi, W.; Sun, S.; Wu, M.; Catano, B.; Li, W.; Wang, J.; Guo, H.; Xing, Y. Tetrahedron Lett.2015, 56, 468.

24 Wang, N.-N.; Huang, L.-R.; Hao, W.-J.; Zhang, T.-S.; Li, G.; Tu, S.-J.; Jiang, B. Org. Lett.2016, 18, 1298.

25 Shiosaki, K.; In Comprehensive Organic Synthesis, B. M. Trost, I. Fleming, Ed. Oxford, Pergamon, 1991; Vol. 2. ch. 3.7, pp 865.

26 Braverman, S. C., M. ;In Comprehensive Organic Synthesis, Knochel, P., Molander, G. A.Eds.; Elsevier, Amsterdam, 2014; Vol. II., ch. 3.18, pp 887.
27 Koduri, N. D.; Hileman, B.; Cox, J. D.; Scott, H.; Hoang, P.; Robbins, A.; Bowers, K.; Tsebaot, L.; Miao, K.; Castaneda, M.; Coffin, M.; Wei, G.; Claridge, T. D. W.; Roberts, K. P.; Hussaini, S. R. RSC Adv.2013, 3, 181.

28 Bachi, M. D.; Breiman, R.; Meshulam, H. J. Org. Chem.1983, 48, 1439.

29 Campbell, J. A.; Rapoport, H. J. Org. Chem.1996, 61, 6313.

30 Singh, S.; Köhler, J. M.; Schober, A.; Groß, G. A. Beilstein J.

Org. Chem.2011, 7, 1164.

31 Kim, G.; Chu-Moyer, M. Y.; Danishefsky, S. J.; Schulte, G. K. J. Am. Chem. Soc.1993, 115, 30.

32 Fang, F. G.; Feigelson, G. B.; Danishefsky, S. J. Tetrahedron Lett.1989, 30, 2743.

33 Padwa, A.; Kinder, F. R.; Zhi, L. Synlett1991, 287.

34 Koduri, N. D.; Scott, H.; Hileman, B.; Cox, J. D.; Coffin, M.; Glicksberg, L.; Hussaini, S. R. Org. Lett.2012, 14, 440.

35 Koduri, N. D.; Wang, Z.; Cannell, G.; Cooley, K.; Lemma, T. M.; Miao, K.; Nguyen, M.; Frohock, B.; Castaneda, M.; Scott, H.; Albinescu, D.; Hussaini, S. R. J. Org. Chem. 2014, 79, 7405.

36 Edwankar, R. V.; Edwankar, C. R.; Namjoshi, O. A.;

Deschamps, J. R.; Cook, J. M. J. Nat. Prod.2012, 75, 181.

37 Chemler, S. R. Science 2013, 341, 624.

38 Sharma, A.; Besnard, C.; Guenee, L.; Lacour, J.Org. Biomol. Chem.2012, 10, 966.

39 Fructos, M. R.; Belderrain, T. R.; Nicasio, M. C.; Nolan, S. P.; Kaur, H.; Diaz-Requejo, M. M.; Perez, P. J. J. Am. Chem. Soc.2004, $126,10846$.

40 Inglesi, M.; Nicola, M.; Magnetti, S. Farmaco1990, 45,

1327.

41 Mechelke, M. F.; Meyers, A. I. Tetrahedron Lett.2000, 41,

4339.

42 Michael, J. P.; de Koning, C. B.; van der Westhuyzen, C. W. Org. Biomol. Chem.2005, 3, 836.

43 de Koning, C. B.; Michael, J. P.; Riley, D. L.

Heterocycles2009, 79, 935.

44 Roth, M.; Dubs, P.; Götschi, E.; Eschenmoser, A. Helv.

Chim. Acta1971, 54, 710.

45 Eschenmoser, A. Helv. Chim. Acta2015, 98, 1483.

46 Blaser, H.-U.; Winnacker, E.-L.; Fischli, A.; Hardegger, B.;

Bormann, D.; Hashimoto, N.; Schossig, J.; Keese, R.; Eschenmoser, A. Helv. Chim. Acta2015, 98, 1845.

47 Yamada, Y.; Wehrli, P.; Miljkovic, D.; Wild, H.-J.; Bühler, N.; Götschi, E.; Golding, B.; Löliger, P.; Gleason, J.; Pace, B.; Ellis, L.; Hunkeler, W.; Schneider, P.; Fuhrer, W.; Nordmann, R.;

Srinivasachar, K.; Keese, R.; Müller, K.; Neier, R.; Eschenmoser, A. Helv. Chim. Acta2015, 98, 1921.

48. General experimetal for the synthesis of enaminones: 5 mol\% (CuOTf)2.Tol complex was weighed in a screw capped reaction vial. The vial was purged with argon. A solution of thioamide $(0.2 \mathrm{mmol})$ in $1.0 \mathrm{ml}$ dry 1,2-dichloroethane was transferred to a vial containing a diazo compound $(0.26 \mathrm{mmol})$. The well mixed solution of thioamide and diazo compound was added to the vial containing the catalyst. The vials containing the starting materials were washed twice with $0.5 \mathrm{ml}$ of dry 1,2-dichloroethane and the contents were transferred to the reaction vial. The reaction mixture was heated at $90^{\circ} \mathrm{C}$. Once the reaction was complete (as observed by the TLC analysis), the solvent was evaporated, and the crude product was purified by the silica gel column chromatography. 


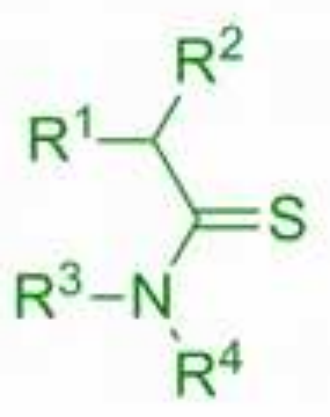

$+\mathrm{N}_{2}=\overbrace{\mathrm{R}^{6}}^{\mathrm{R}^{5}}$

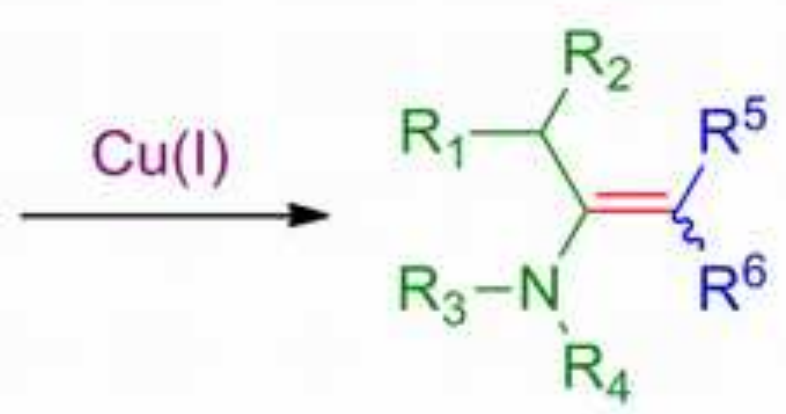

high chemoselectivity broad substrate scope up to $93 \%$ yield catalytic sulfur extrusion 